\title{
ADDENDUM
}

\section{Multidrug therapy cost: a hypothetical analysis}

\author{
C R REVANKAR \\ Bombay Leprosy Project, Vidnyan Bhuwan, 11 VN Purav Marg, \\ Sion-Chunabhatti, Bombay 400 022, India
}

\section{Introduction}

Multidrug therapy (MDT) has been widely accepted as an effective intervention tool for the time being in leprosy control programmes to overcome problems like dapsone resistance, drug persistors and poor drug compliance for long-term treatment. Various authentic bodies like WHO,${ }^{23}$ ILEP, ${ }^{11}$ Indian Association of Leprologists (IAL) ${ }^{12}$ and Borstel $^{2}$ recommended their drug regimens to be suitable for all situations of leprosy control programmes. Recently another drug regimen called Isoprodian-RMP (ISO-R-rifampicin is combined in Isoprodian) has been introduced on a multicentre trial basis by the German Leprosy Relief Association. ${ }^{8}$ Pattyn et al. ${ }^{17}$ recommended a regimen for developed countries similar to WHO, but advocated administration of daily rifampicin instead of a monthly pulse. A lot of experience has been gained over the past 3 years in using different regimens in field conditions, and preliminary reports are available on the efficacy of drug combinations and operational aspects of WHOILEP and IAL regimens. ${ }^{9,10,15,18,19,20}$ Effectiveness of Isoprodian with rifampicin (Borstal therapy) in a mass scale Malta-Project has been reported ${ }^{4}$ and subsequent long-term follow up evaluation has been reported recently. ${ }^{7,14}$ No such data are yet available on Isoprodian-RMP (ISO-R) and other regimen. Whatever type of regimen one is likely to implement for a mass scale programme to meet the objectives, in addition to efficacy, feasibility, acceptability, availability of drugs, it is very essential to consider the cost factor of both drug and operational costs of mass scale multidrug therapy programmes in view of financial constraints. This is essential as we do not have definite data on the most effective drug regimen for a short duration with least toxicity meeting the objectives of multidrugs, period required for curing cases, relapse rates and other epidemiological data to launch a global leprosy eradication programme, which will be essential to eradicate leprosy from any country as man becomes a reservoir of infection whose movement cannot be stopped. 
No reports are yet available on the cost-effectiveness of MDT programmes except one report, ${ }^{1}$ where this has been worked out in comparison to DDS monotherapy for 5 years which is to be considered as tentative. As the necessary data are not available on MDT to work out cost-effectiveness, only the drug cost is worked out.

\section{Hypothetical basis for cost factor workout}

To work out the cost factors in all the above mentioned regimens for a mass programme, it is presumed that all the regimens would be effective in both multiand paucibacillary leprosy, as all these combinations have rifampicin which is a strong bactericidal drug. It is also presumed that all these regimens are well accepted and tolerated (all these regimens are being used by this project, where it is observed that the majority of patients under different groups tolerate these well). With these presumptions, drug cost has been worked out for currently available multidrug combinations for mass scale implementation in a hyperendemic situation where prevalance rate is 10 and above per thousand population.

For calculation purpose it is presumed that multidrug therapy has been started in a population of 4,000,000 and equally divided for the following four regimens with a prevalance rate of 10 per thousand. 1000 cases are expected for each group. 1, Isroprodian-RMP (ISO-R); 2, Borstel; 3, WHO/ILEP; 4, IAL.

\section{Cost of the drugs (in Indian currency-approximate)}

As Isoprodian and Isoprodian-RMP is not yet available in the Indian market, the cost per tablet has been worked out exclusively on a proforma invoice sent by Saarstickstoff-Fatol GMBH 6685 Schiffweller, Federal Republic of Germany and the value shown in DM has been converted into Indian rupees. As the rest of the drugs are available in India, the cost is worked out on current rates: Isoprodian, Rs. 0.22 per tablet; Isoprodian-RMP (ISO-R), Rs. 0.25 per tablet; rifampicin $(150 \mathrm{mg})$, Rs. 0.80 per capsule; clofazimine, Rs. 0.70 per capsule; DDS $(100 \mathrm{mg})$, Rs. 0.05 per tablet.

\section{Estimation of caseload}

For chemotherapy purposes WHO classifies all the LL, BL, BB patients with $\geqslant 2$ $\mathrm{BI}$ as multibacillary and the rest as paucibacillary. (I, TT, BT). ${ }^{22}$ However, in view of difficulties in the programmes in developing countries fore reliable smear reports with Ridley's scale, the Indian Association of Leprologists group simplified this classification and designated all the positive smears (LL, BL, BB) 
Table 1. Regimen cost analysis per patient (Indian currency)

\begin{tabular}{|c|c|c|c|c|}
\hline & $\begin{array}{c}\text { ISO-R } \\
\text { (GLRA) }\end{array}$ & $\begin{array}{l}\text { Isoprodian } \\
\text {-rifampicin } \\
\text { (Borstel) }\end{array}$ & WHO-ILEP & IAL \\
\hline \multicolumn{5}{|c|}{ Multibacillary (2 years) } \\
\hline Adult & 720.00 & 2628.00 & 718.00 & 825.00 \\
\hline Child & 360.00 & 1314.00 & 359.00 & 413.00 \\
\hline \multicolumn{5}{|c|}{ Paucibacillary (6 months) } \\
\hline Adult & 180.00 & 657.00 & 28.00 & 28.00 \\
\hline Child & 90.00 & 329.00 & 14.00 & 14.00 \\
\hline
\end{tabular}

Cost is worked out for a minimum period of 2 years in multibacillary cases and 6 months in paucibacillary cases as per WHO and recommendation. $^{22}$

as multibacillary and the negative smears (I, TT, BT) as paucibacillary. ${ }^{12}$ Hence this criteria hs been applied for this estimation.

The following data obtained from the Bombay Leprosy Project field were collected over the past few years to work out the caseload (though it was not statistically collected data):

Based on the above figures (Table 2), the following figures have been worked out.

Prevalence rate: 10 and above per thousand population.

Population covered under multidrug therapy: $1,000,000$ in each regimen.

Table 2. Age and type distribution of leprosy cases.

\begin{tabular}{lcccc}
\hline Age group & Total & $\begin{array}{c}\text { Multibacillary } \\
(\mathrm{MB})^{*}\end{array}$ & $\begin{array}{c}\text { Paucibacillary } \\
(\mathrm{PB}) \dagger\end{array}$ & $\begin{array}{c}\text { Paucibacillary* } \\
\text { (multilesional) }\end{array}$ \\
\hline Adult & 2948 & 371 & 2577 & 2061 \\
& $(70 \%)$ & $(13 \%)$ & $(87 \%)$ & $(80 \%)$ \\
Child & 1321 & 19 & 1302 & 260 \\
& $(30 \%)$ & $(2 \%)$ & $(88 \%)$ & $(20 \%)$ \\
\hline Total & 4269 & 390 & 3879 & 2321 \\
\hline
\end{tabular}

* Multibacillary type (smear positive): adult, $13 \%$ of total adult cases; child, $2 \%$ of total child cases.

$\dagger$ Paucibacillary type (smear negative): adult, $87 \%$ of total adult cases; child, $98 \%$ of total child cases.

$\ddagger$ Paucibacillary type with 4 and more lesions: adult, $80 \%$ of adult paucibacillary cases; child, $20 \%$ of child paucibacillary cases. 
Table 3. Age and type caseload.

\begin{tabular}{lcccc}
\hline & $\begin{array}{c}\text { Total } \\
\text { no. of } \\
\text { cases }\end{array}$ & $\begin{array}{c}\text { Multibacillary } \\
\text { (MB) }\end{array}$ & $\begin{array}{c}\text { Paucibacillary } \\
\text { (PB) }\end{array}$ & $\begin{array}{c}\text { Paucibacillary } \\
\text { with 4 and more } \\
\text { lesions }\end{array}$ \\
\hline Adult & 700 & 91 & 609 & 240 \\
Child & 300 & 6 & 294 & 60 \\
\hline Total & 1000 & 97 & 903 & 300 \\
\hline
\end{tabular}

Total number of patients: 1000 in each group.

Table 4 shows the total cost of the drugs used in different regimen to complete minimum period of 2 years and 6 months of adequate treatment of multi and paucibacillary leprosy cases respectively, as per WHO recommendation. ${ }^{22}$ No operational cost is included. The new cases occurring during the subsequent years, and deletion due to various reasons are not considered for this calculations as sufficient data is not available under each drug regimen. Cost of treating multilesional paucibacillary cases like multibacillary patients is not considered to workout cost, which will definitely increase the size of the budget.

1 The drug cost analysis showed that out of all the regimen recommended for control programmes WHO-ILEP regimen worked out to be cheaper for completing minimum treatment of 2 years and 6 months in multibacillary and paucibacillary types respectively.

2 Initial 21 days intensive therapy with rifampicin in IAL regimen increases the cost. The advantage of this initial therapy is not clearly established. However, a recent preliminary investigation where untreated high multibacillary types treated with WHO and IAL schedules did not show any significant difference in

Table 4. Drug cost in different regimen (Indian Rupees)

\begin{tabular}{lrrrr}
\hline & $\begin{array}{c}\text { Isoprodian- } \\
\text { RMP } \\
\text { (GLRA) }\end{array}$ & $\begin{array}{c}\text { Isoprodian } \\
\text { rifampicin } \\
\text { (Borstel) }\end{array}$ & WHO/ILEP & IAL \\
\hline Multibacillary (2 years) & & & & \\
$\quad$ Adult (91 cases) & $65,520.00$ & $239,148.00$ & $65,338.00$ & $75,075.00$ \\
Child (6 cases) & $2,160.00$ & $7,884.00$ & $2,154.00$ & $2,478.00$ \\
Paucibacillary (6 months) & & & & \\
Adult (609 cases) & $109,620.00$ & $100,113.00$ & $17,052.00$ & $17,052.00$ \\
Child (294 cases) & $26,460.00$ & $96,726.00$ & $4,116.00$ & $4,116.00$ \\
\hline Total & $203,760.00$ & $743,871.00$ & $88,660.00$ & $98,721.00$ \\
\hline
\end{tabular}


loss of viability of Mycobacterium leprae demonstrated by mouse footpad and in vitro techniques. ${ }^{21}$ However this is to be confirmed on a larger sample. An analysis of bacteriological conversion rate in 146 (IAL schedule) and 103 (WHO schedule) patients in the Bombay Leprosy Project after 24 pulse doses showed that $59(40 \%)$ and $64(62 \%)$ bacterial negativity in IAL and WHO group respectively. These findings question the need for intensive therapy in IAL schedule as well as usefulness of daily rifampicin in Borstel and Isoprodian-RMP (ISO-R) combination, which increases the cost.

3 However the Malta Project where Borstel therapy was implemented and long term follow up for more than 10 years showed no relapses and occurrence of new cases except in 10 cases where solid bacilli could be demonstrated in finger smears which are considered as persisters. ${ }^{14}$ Such longitudinal population based studies would be essential in other regimens also to study relapse rate, incidence rate and need to continue treatment till smear negativity before any schedule is accepted as ideal even from the point of cost which is one of the important constraints in any control programme, especially for voluntary agencies.

4 Isoprodian along with rifampicin is also found to be effective in tuberculosis. ${ }^{5}$ This would be an added advantage for mass chemotherapy programmes using Isoprodian containing regimen where pulmonary tuberculosis cannot be ruled out on a mass scale; which has to be done if monthly pulse therapy of rifampicin is to be administered or associated tuberculosis is to be treated. The combined chemotherapy programme for tuberculosis and leprosy in Paraguay ${ }^{6}$ and Tanzania ${ }^{16}$ may evaluate effectiveness of Isoprodian combinations in the light of cost factor in areas where both these diseases are endemic.

5 Supervised administration of rifampicin has been advocated to prevent irregular intake of this drug and emergency of rifampicin resistant strains. In the Malta Project, where daily rifampicin was administered without supervison, no case emerging with resistance to any one of the drugs included in Borstel therapy has been reported so far. On the contrary intermittent administration of rifampicin may give rise to adaptive resistance. ${ }^{3}$ Long term surveillance of cases included under WHO-IAL therapy may provide useful data on this aspect.

6 To monitor drug intake (compliance) a simple test like 'Tile test' has been devised for field conditions. ${ }^{13}$ This test monitors only the intake of DDS. However for rifampicin and clofazimine, no such simple tests have been devised. In this respect the drug ISO- $\mathrm{R}$ will have an added advantage, i.e. if tile tests can detect DDS in urine, it indicates that the patient has swallowed all four drugs. Similarly in the case of Isoprodian the patient swallows three drugs including prothionamide which is also a strong bactericidal drug.

Ultimately it is left to the programme managers to choose any type of drug regimen recommended by expert groups for eradication of leprosy and/or tuberculosis (if a combined programme is operated) considering cost effectiveness of any drug combination over number of years of programme. This has been 
rightly pointed out by Askew ${ }^{1}$ and Freerksen and Rosenfeld ${ }^{5}$ comparing multidrug therapy programme to monotherapy with DDS.

Longitudinal population based studies with different drug regimen are required for comparative evaluation of these drug regimen with respect to cost effectiveness. However in the meantime the available data on these different schedules could be compared from the point of bacteriological conversion rate in multibacillary types and clinical response in paucibacillary type. In addition to this comparative data on toxicity and incidence of reaction is also essential.

\section{Acknowledgments}

The author is very thankful to Dr R Ganapati, Director, Bombay Leprosy Project for his kind permission to use project data to prepare this paper and publish it.

Thanks are also due to Dr (Mrs) Asha Shenoy, Medical Officer, Bombay Leprosy Project for her kind assistance.

\section{References}

1 Askew AD. Managerial implications of Multidrug Therapy, Editorial. Lepr Rev, 1985; 56: 8997.

2 Borstel. Circular from German Leprosy Relief Association 1983.

${ }^{3}$ Chatterjee BR. Drug resistance and Multidrug therapy in leprosy. Editorial. Lepr India, 1982; 54: 402-11.

${ }^{4}$ Freerksen E, Rosenfeld M. Leprosy Eradication Project of Malta. Chemotherapy 1977; 23: 35686.

${ }^{5}$ Freerksen E, Rosenf eld M. Leprosy-Tuberculosis Eradication-Principles, Practical Implementation. Published by Excerpta Medica, Amsterdam, 1980; 1-53.

${ }^{6}$ Freerksen E, Rosenfeld M. Eradication of Tuberculosis and Leprosy using ChemotherapyIncluding a short report on the 'Malta Project' and the 'Paraguay Project', Quaderni di cooperazione Sanitoria-Health Cooperation Papers No. 1, 83-90.

7 Freerksen E. Report on the Malta-Project (Leprosy Eradication Programme on Malta State as per July 31, 1984). Circular from GLRA, 1984.

${ }^{8}$ GLRA. Circular from German Leprosy Relief Association, 1984.

9 Ganapati R, Revankar CR, Gawade PB. Multidrug Therapy for Multibacillary LeprosyExperience in Bombay. Abstract from the Book of Abstract of the XII International Leprosy Congress, New Delhi 1984, Indian J Lepr (Supplement), 1984; 56.

${ }^{10}$ Ganapati R, Naik SS, Revankar CR. Raju Vartak, Desai AP, Panvalkar NA. Supervised administration of Multidrug Therapy in Leprosy Colonies through Volunteers-A bacteriological assessment, 1985. Paper presented at Western Regional Leprosy Workers' Conference, Goa, India. November 1985.

11 ILEP. Implementation of MDT in Leprosy Control Programme, 1982.

12 Indian Association of Leprologists, 1982. Consensus on treatment regimen in leprosy and problems of drug delivery. Indian J lepr, 1984; 56: 158.

${ }^{13}$ Irudayaraj PP, Lilly L, Aschhoff M, Balkrishnan S. Application of 'Tile Reaction' test for screening Dapsone in urine. Lepr India, 1983; 55: 654-64. 
14 Jopling WH, Ridley MJ, Bounici E, Depasquale G. A follow up investigation of the Malta Project. Lepr Rev, 1985; 55: 247-53.

15 Nilkanta Rao MSN, Yellapurkar MV. Multidrug therapy for Multibacillary cases in Wardha, Dist. Maharashtra, India. Indian J lepr, 1985; 57: 159-63.

16 Nkinda JJ. Tuberculosis/Leprosy Control Programme Tanzania, 1985. WHO-Consulation on implementation of Multidrug therapy for Leprosy Control, Geneva, October 1985. LCP/ Cons/WP/85.1.

17 Pattyn SR, Ellard GA, Freerksen E, Grosset J, Huikeshoven H, Leikar DL, Noordeen SK, Seydel JK. Report of the Sub-group on Therapy, 1983. Quaderni di Cooperazione Sanitaria. Health Co-operation Papers No. 1, 187-9.

18 Pai Rashmi R, Revankar CR, Ganapati R. Bacteriological assessment of multibacillary cases under Multidrug therapy, 1985. Paper presented at the Western Regional Leprosy Workers' Conference, Goa, India, November 1985.

19 Revankar CR, Ganapati R, Naik DD. Multidrug therapy for Paucibacillary leprosyExperience in Bombay, Abstract from the Book of Abstract of the XII International Leprosy Congress, New Delhi. 1984. Indian J lepr (Supplement), 1984. 55.

${ }^{20}$ Revankar CR. Karjivkar Vidya G, Gurav VJ, Ganapati R. Clinical assessment of Paucibacillary leprosy patients receiving short term Multidrug therapy-A preliminary report, 1985. Paper presented at Western Regional Leprosy Workers' Conference, Goa, India, November 1985.

${ }^{21}$ Revankar CR, Mahadevan PR, Ganapati R. Comparative study of Efficacy of WHO and IAL Multidrug Therapy for Leprosy In-vivo and In-Vitro Study, 1986. Paper presented at the XIV Biennial Conference of Indian Association of Leprologists, Jabalpur, India January 1986.

22 WHO. Chemotherapy of Leprosy for Control Programme TRS. 675, 1982. 